\title{
Publisher Correction: The $\beta 20-\beta 21$ of gp120 is a regulatory switch for HIV-1 Env conformational transitions
}

\author{
Alon Herschhorn ${ }^{1,2}$, Christopher Gu', Francesca Moraca ${ }^{3}$, Xiaochu Ma4, Mark Farrell ${ }^{5}$, Amos B. Smith, III ${ }^{5}$, \\ Marie Pancera ${ }^{6}$, Peter D. Kwong ${ }^{6}$, Arne Schön 7 , Ernesto Freire ${ }^{7}$, Cameron Abrams (1 ${ }^{3}$, Scott C. Blanchard ${ }^{8}$, \\ Walther Mothes ${ }^{4} \&$ Joseph G. Sodroski $i^{1,2,9}$
}

Correction to: Nature Communications https://doi.org/10.1038/s41467-017-01119-w, published online 19 October 2017

The original version of this Article contained an error in the spelling of the author Amos B. Smith, III, which was incorrectly given as Amos B. SmithIII. This has now been corrected in both the PDF and HTML versions of the Article.

Published online: 08 January 2018 \begin{abstract}
reproduction in any medium or format, as long as you give appropriate credit to the original author(s) and the source, provide a link to the Creative Commons license, and indicate if changes were made. The images or other third party material in this article are included in the article's Creative Commons license, unless indicated otherwise in a credit line to the material. If material is not included in the article's Creative Commons license and your intended use is not permitted by statutory regulation or exceeds the permitted use, you will need to obtain permission directly from the copyright holder. To view a copy of this license, visit http://creativecommons.org/licenses/by/4.0/.
\end{abstract}

(c) (i) Open Access This article is licensed under a Creative Commons Attribution 4.0 International License, which permits use, sharing, adaptation, distribution and

() The Author(s) 2018

\footnotetext{
${ }^{1}$ Department of Cancer Immunology and Virology, Dana-Farber Cancer Institute, Boston, MA 02215, USA. ${ }^{2}$ Department of Microbiology and Immunobiology, Harvard Medical School, Boston, MA 02115, USA. ${ }^{3}$ Department of Chemical and Biological Engineering, Drexel University, Philadelphia, PA 19104, USA. ${ }^{4}$ Department of Microbial Pathogenesis, Yale University School of Medicine, New Haven, CT 06536, USA. ${ }^{5}$ Department of Chemistry, University of Pennsylvania, Philadelphia, PA 19104, USA. ${ }^{6}$ Vaccine Research Center, National Institute of Allergy and Infectious Diseases, National Institutes of Health, Bethesda, MD 20892, USA. 7 Department of Biology, Johns Hopkins University, Baltimore, MD 21218, USA. ${ }^{8}$ Department of Physiology and Biophysics, Weill Cornell Medical College of Cornell University, New York, NY 10065, USA. ${ }^{9}$ Department of Immunology and Infectious Diseases, Harvard T. H. Chan School of Public Health, Boston, MA 02115, USA. Correspondence and requests for materials should be addressed to A.H. (email: alon_herschhorn@dfci.harvard.edu) or to J.G.S. (email: joseph_sodroski@dfci.harvard.edu)
} 